\title{
Theoretical Power Output of Thermoelectric Power Generator based on Metal Oxide Semiconductor
}

\author{
Mohamad Adam Shah Mohd Roseny ${ }^{1}$, Suhasini Sathiyamoorthy ${ }^{2}$, \\ Mohd Faizul Mohd Sabri ${ }^{1}$, Suhana Mohd Said ${ }^{1}$, Pandiyarasan Veluswamy ${ }^{3}$, Faiz Salleh ${ }^{1 *}$ \\ ${ }^{1}$ Faculty of Engineering, Universiti Malaya, Kuala Lumpur 50603, Malaysia \\ ${ }^{2}$ Department of Electronics and Communication Engineering, SRM Institute of Science and Technology, \\ Kattankulathur 603203, India \\ ${ }^{3}$ School of Interdisciplinary Design and Innovation, Indian Institute of Information Technology Design and \\ Manufacturing Kancheepuram, Chennai 600127, India
}

\begin{abstract}
Optimizing the structure and material combination of thermoelectric power generators (TEGs) is essential to their efficiency. In order to develop an efficient TEG based on an oxide semiconductor, we theoretically simulated the power output of a TEG based on potential oxide semiconductors $\left(\mathrm{ZnO}, \mathrm{TiO}_{2}\right.$, and $\left.\mathrm{CuO}\right)$ combined with electrode materials $\mathrm{Au}, \mathrm{Ag}, \mathrm{Cu}$, graphene, graphite, ITO, IZO, and AZO), and determined the influence of this material combination on the TEG's power output. In this study, the power output was evaluated from simulated heat distribution and output voltage of a single leg and thermopiles using a simulator. The combination of $\mathrm{ZnO}$ and graphene showed the highest power output. This is likely due to the high thermal conductivity of graphene which allowed a high temperature difference in the $\mathrm{ZnO}$. Moreover, the power output increased with decreasing electrode thickness, which allowed high output voltage to be generated by the thermoelectric material. The power density of the TEG consisting of several thermopiles based on $\mathrm{ZnO}$ and graphene materials was $29 \mathrm{~mW} / \mathrm{cm}^{2}$, which was comparable with that of the reported TEG consisting of Te-based materials. Thus, a TEG based on oxide semiconductor materials could be developed to reduce the use of harmful thermoelectric materials.
\end{abstract}

Keywords: $\quad$ Electrode; Oxide semiconductor; Thermoelectric material; Thermoelectric power generator

\section{Introduction}

The increased demand for electricity has caused major environmental issues, such as resource depletion, pollution, and climate change, due to the use of conventional electrical power generation. These issues have encouraged researchers to develop alternative technologies that use renewable and clean energy resources when generating electricity. Of these, thermoelectric technology is one of the best at directly converting clean energy resources into electricity. Thermoelectric power generators (TEGs) apply thermoelectric effects to directly convert waste heat into electricity, and many researchers have focused on their development due to their known advantages, such as a long lifespan, noiselessness, and low maintenance needs (Musiał et al., 2016). However, the thermoelectric conversion 
efficiency of TEGs is still low compared to other clean technologies, such as solar cells. Moreover, most commercial TEGs are fabricated using rare and harmful materials, such as $\mathrm{Bi}_{2} \mathrm{Te}_{3}$ and $\mathrm{PbTe}$. Thus, developing an efficient TEG using a low-cost, simple fabrication process and environmentally friendly materials is important.

The introduction of nanostructure, optimization of TEG structure, and formulation of new thermoelectric materials are approaches that have been used by researchers to improve the power output of TEGs. Specifically, Te-based thermoelectric materials have shown improvements in power output when applied to TEGs. Thus, commercialized TEGs are mostly based on these materials due to their high power output. They generate a power density of a few $\mathrm{mW} / \mathrm{cm}^{2}$ under temperature differences of a few tens to hundreds Kelvin in low-temperature application regions (Narducci, 2019). In contrast, oxide materials are abundant, low cost, non-toxic, and chemically stable at high temperatures, which makes them ideal materials for fabricating TEGs (Vieira et al., 2021). Thus, a number of researchers have reported the used of oxide materials for realizing an efficient TEG. For example, Matsubara fabricated a TEG based on $\mathrm{Ca}_{0.92} \mathrm{La}_{0.08} \mathrm{MnO}_{3}$ and $\mathrm{Ca}_{2.75} \mathrm{Gd}_{0.25} \mathrm{Co}_{4} \mathrm{O}_{9}$ as $\mathrm{n}$ - and p-type thermoelectric legs, respectively, and they reported a power output of $21 \mathrm{~mW} / \mathrm{cm}^{2}$ at a temperature of $\sim 851 \mathrm{~K}$ (Matsubara et al., 2001). In 2018, Kanas reported a higher power output of $23 \mathrm{~mW} / \mathrm{cm}^{2}$ at a much higher temperature of $\sim 1173 \mathrm{~K}$ using a TEG fabricated with $\mathrm{CaMnO}_{3-\delta}-\mathrm{CaMn}_{2} \mathrm{O}_{4}$ and $\mathrm{Ca}_{3} \mathrm{Co}_{4-x} \mathrm{O}_{9+\delta}$ as the $\mathrm{n}$ - and p-type thermoelectric legs, respectively (Kanas et al., 2018). These promising power output values were obtained in a hightemperature region, showing that the oxide material is well suited for application in these temperature regions. Therefore, clarifying the potential of oxide materials for application in near-room-temperature regions is necessary to support current self-powered technologies that are used in these temperature regions.

TEGs' structure and appropriate material combination also play an important role in improving their power output. Kanas reported an enhancement of a TEG's power output to $28.9 \mathrm{~mW} / \mathrm{cm}^{2}$ by improving the p-n junction and the cell design (Kanas et al., 2020). Lim reported a comparable power density of $93.2 \mathrm{~mW} / \mathrm{cm}^{2}$ in a TEG based on $\mathrm{Ca}_{3} \mathrm{Co}_{4} \mathrm{O}_{9}, \mathrm{CaMnO}_{3}$, and $(\mathrm{Zn})_{7} \mathrm{In}_{2} \mathrm{O}_{3}$ materials and found that the contact resistance between electrode materials greatly affected the power output of the TEG in high-temperature regions (Lim et al., 2013). The influence of geometrical design and contact resistance on TEG performance has also been observed in commercial TEGs based on Te materials. Ebling found that contact resistance governs TEG performance and that performance is not increased by varying the leg length (Ebling et al., 2010). In a theoretical work on a TEG based on SnSe and $\mathrm{Bi}_{0.5} \mathrm{Sb}_{1.5} \mathrm{Te}_{3}$, it is also observed that the performance of TEGs can be improved by decreasing contact resistance (Luo and Kim, 2019). Thus, clarifying the suitable combination of available oxide semiconductors and electrode materials, as well as the influence of contact resistance and electrode thickness on the TEG's performance, are significantly important for formulating an efficient TEG based on oxide materials, especially for room-temperature application regions. Therefore, in order to clarify the best combination of potential oxide semiconductor materials and available electrode materials for room-temperature application TEGs, this study simulated the power output of a single-leg and thermopile-structured TEG with a combination of $\mathrm{ZnO}, \mathrm{TiO}_{2}$, and $\mathrm{CuO}$ as thermoelectric materials and $\mathrm{Au}, \mathrm{Ag}, \mathrm{Cu}$, graphene, graphite, ITO, IZO, and AZO as electrode materials. The influence of this material combination on the TEG's power output was then discussed in terms of contact resistance, thermoelectric properties, and thickness of the electrode materials. 


\section{Methods}

Figure 1 shows the three-dimensional structural models used in the simulation. In order to clarify the optimum combination of thermoelectric and electrode materials, a single leg of a thermopile consisted of a thermoelectric material sandwiched by electrode materials with a dimension of width $\times$ thickness $\times$ depth $(\mathrm{W} \times \mathrm{T} \times \mathrm{D})$ is set, as shown in Figure 1a. The dimension of the thermoelectric and electrode materials were set to $1.6 \times$ $1.4 \times 1.4$ and $0.2 \times 1.4 \times 1.4 \mathrm{~mm}^{3}$, respectively. The type of material and, thermoelectric and material properties used in the simulation are listed in Tables 1 and 2, respectively. Figure $1 \mathrm{~b}$ shows the structure of the TEG used in the simulation, in which four thermopiles were connected in a series using $\mathrm{Cu}$. Each thermopile consisted of n- and p-type ZnO legs with graphene as the electrode. COMSOL software was used to simulate the heat and open-circuit voltage considering the conservation of charge and heat transfer in solids with respect to the corresponding thermoelectric and material properties shown in Tables 1 and 2, respectively. The partial differential heat and current equations were solved using the finite element method. For steady-state thermoelectricity, the following governing equations were used:

$$
\begin{gathered}
\rho \mathrm{C}_{\mathrm{p}} \mathrm{u} \cdot \nabla \mathrm{T}+\nabla \cdot \mathrm{q}=\mathrm{Q}+\mathrm{Q}_{\text {ted }} \\
\mathrm{J}=\sigma(-\Delta \mathrm{V}+-\sigma \mathrm{S} \nabla \mathrm{T})
\end{gathered}
$$

where Equations 1 and 2 represent the heat and current equations, respectively. $\rho$ is the density of material, $C_{p}$ is the specific heat capacity at constant stress, $u$ is the velocity vector of translational motion, $\mathrm{Q}$ is the additional heat sources, $\mathrm{Q}_{\text {ted }}$ is the thermoelastic damping, $\mathrm{V}$ is the electric potential, $\mathrm{S}$ is the Seebeck coefficient, $\sigma$ is the electrical conductivity, $\mathrm{T}$ is the temperature, and $\mathrm{q}=-\mathrm{k} \nabla \mathrm{T}$, where $\mathrm{k}$ is the thermal conductivity. A heat source was applied at the top electrode with a temperature of $360 \mathrm{~K}$. The heat was convected to the bottom electrode and radiated to the ambiance with a heat flux of $1000 \mathrm{~W} / \mathrm{m}^{2}$.

The simulated open-circuit voltage was validated through comparison with the calculated open-circuit voltage considering the Seebeck effect of the thermoelectric and electrode materials connected in the series. The steady-state power output was evaluated using the following equations (Musiał et al., 2016):

$$
\begin{gathered}
I=\frac{V_{O C}}{R_{L}+R} \\
P=I^{2} R
\end{gathered}
$$

where $V_{\text {oc }}$ is the simulated open circuit voltage, $R$ is the total resistance of the leg, $R_{L}$ is the resistance of the load, and I is the current. The power output, $\mathrm{P}$ (discussed later in this article), was assumed to be the maximum power output when $R=R_{L}$.

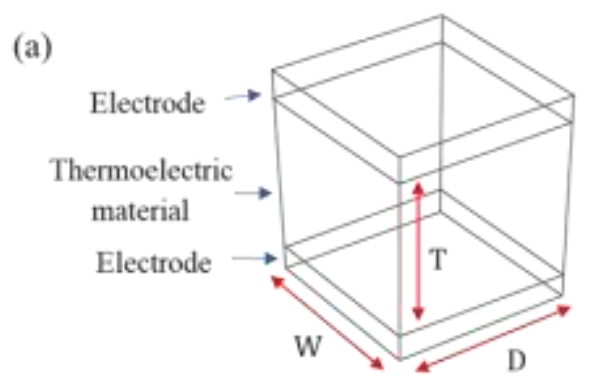

(b)

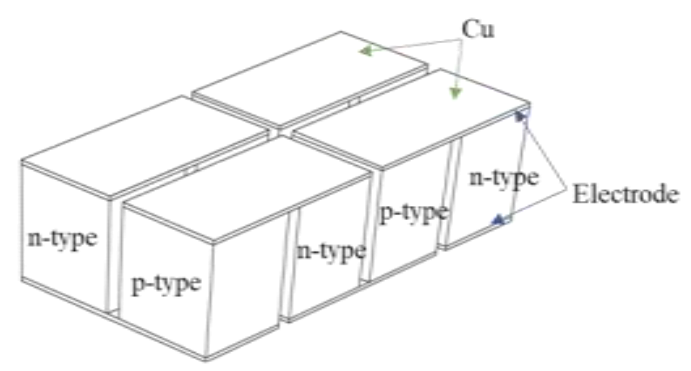

Figure 1 Structure of: (a) a single leg; and (b) thermopile-structured TEG 
Table 1 Thermoelectric properties of thermoelectric and electrode materials

\begin{tabular}{cccc}
\hline $\begin{array}{c}\text { Electrode/ } \\
\text { Thermoelectric Materials }\end{array}$ & $\begin{array}{c}\text { Seebeck Coefficient, } \mathrm{S} \\
(\mu \mathrm{V} / \mathrm{K})\end{array}$ & $\begin{array}{c}\text { Electrical } \\
\text { Conductivity, } \sigma \\
(\mathrm{S} / \mathrm{m})\end{array}$ & $\begin{array}{c}\text { Thermal } \\
\text { Conductivity, } \mathrm{k} \\
(\mathrm{W} / \mathrm{mK})\end{array}$ \\
\hline $\mathrm{Ag}$ & $1.51^{\mathrm{a}}$ & $6.13 \times 10^{7 \mathrm{k}}$ & $429^{\mathrm{g}}$ \\
$\mathrm{Au}$ & $1.94^{\mathrm{a}}$ & $4.41 \times 10^{7 \mathrm{k}}$ & $317^{\mathrm{g}}$ \\
$\mathrm{Cu}$ & $1.83^{\mathrm{a}}$ & $5.78 \times 10^{7 \mathrm{k}}$ & $401^{\mathrm{g}}$ \\
Graphene & $10^{\mathrm{b}}$ & $1 \times 10^{51}$ & $4000^{\mathrm{o}}$ \\
Graphite & $-8^{\mathrm{c}}$ & $3448.28^{\mathrm{m}}$ & $500^{\mathrm{o}}$ \\
ITO & $-10^{\mathrm{d}}$ & $4.7 \times 10^{5 \mathrm{~d}}$ & $\sim 10^{\mathrm{p}}$ \\
IZO & $-57^{\mathrm{e}}$ & $1.7 \times 10^{4 \mathrm{e}}$ & $3.4^{\mathrm{q}}$ \\
$\mathrm{AZO}$ & $-18^{\mathrm{f}}$ & $6 \times 10^{4 \mathrm{f}}$ & $1.19^{\mathrm{r}}$ \\
$\mathrm{ZnO}$ & $-350^{\mathrm{g}}$ & $1 \times 10^{3 \mathrm{~g}}$ & $37^{\mathrm{g}}$ \\
TiO2 & $-462^{\mathrm{h}}$ & $384.61^{\mathrm{h}}$ & $6.3^{\mathrm{h}}$ \\
CuO & $520^{\mathrm{i}}$ & $1.5^{\mathrm{i}}$ & $35^{\mathrm{s}}$ \\
Co-doped ZnO & $1477^{\mathrm{j}}$ & $5.88 \times 10^{3 \mathrm{j}}$ & $\sim 37^{\mathrm{j}}$ \\
\hline
\end{tabular}

a(Cusack and Kendall, 1958), b(Amollo et al., 2017), c(Yin et al., 2011), d(Wu et al., 2010), e(Fang et al., 2010), f(Luo et al., 2017), g(Cheng et al., 2009), h(Kitagawa et al., 2010), i(Abinaya et al., 2020), j(Bian et al., 2004), k(Matula, 2009), '(Fang et al., 2020), m(Kausar and Taherian, 2019), n(Ho et al., 2009), o(Vendra and Chrzanowska-Jeske, 2019), p(Thuau et al., 2011), q(Endoh et al., 2011), r(Loureiro et al., 2014), s(Hartung et al., 2015)

Table 2 Material properties of thermoelectric and electrode materials

\begin{tabular}{cccc}
\hline $\begin{array}{c}\text { Electrode/ } \\
\text { Thermoelectric Materials }\end{array}$ & Density, $\rho\left(\mathrm{Kg} / \mathrm{m}^{3}\right)$ & $\begin{array}{c}\text { Relative } \\
\text { Permittivity, } \in\end{array}$ & $\begin{array}{c}\text { Specific Heat } \\
\text { Capacity, } \mathrm{C}_{\mathrm{p}} \\
\text { (J/Kg-K) }\end{array}$ \\
\hline $\mathrm{Ag}$ & $10490^{\mathrm{t}}$ & 1 & $236^{\mathrm{c} 1}$ \\
$\mathrm{Au}$ & $19320^{\mathrm{t}}$ & 1 & $129^{\mathrm{c} 1}$ \\
$\mathrm{Cu}$ & $8930^{\mathrm{t}}$ & 1 & $384^{\mathrm{c} 1}$ \\
Graphene & $\sim 2267$ & $6.9^{\mathrm{w}}$ & $700^{f 1}$ \\
Graphite & $\sim 2267$ & $53^{\mathrm{x}}$ & $838^{\mathrm{h} 1}$ \\
ITO & 7140 & $9^{\mathrm{y}}$ & $\sim 233$ \\
IZO & $5300^{\mathrm{u}}$ & $9^{\mathrm{y}}$ & $1.069 \times 10^{-3 \mathrm{~d} 1}$ \\
$\mathrm{AZO}$ & $\sim 5560^{\mathrm{v}}$ & $\sim 0.2^{\mathrm{z}}$ & $\sim 494$ \\
$\mathrm{ZnO}$ & $\sim 5560^{\mathrm{v}}$ & $\sim 8.5$ & $\sim 494$ \\
TiO2 & 4230 & $114^{\mathrm{a} 1}$ & 683 \\
$\mathrm{CuO}$ & 6310 & $18.1^{\mathrm{b} 1}$ & $531^{\mathrm{e} 1}$ \\
Co-doped ZnO & $\sim 5560^{\mathrm{x}}$ & $\sim 8.5^{\mathrm{e} 1}$ & $\sim 494^{\mathrm{k} 1}$ \\
\hline
\end{tabular}

t(Kremer et al., 2012), u(Bang etal., 2020), v(Han and Shu, 2016), w(Fang et al., 2016), x(Hong et al., 2017), y(Lee et al., 2011), z(Kinsey et al., 2015), a1(Ozaki et al., 2017), b1(Coelho et al., 2019), c1(Carvill., 1994), d1(Ashida et al., 2007), e1(Peyghambarzadeh et al., 2013), f1(Li et al., 2017)

\section{Results and Discussion}

Figure 2 shows the evaluated power output of combination of thermoelectric and electrode materials of a single leg. The filled red circles and green squares represent the ntype $\mathrm{ZnO}$ and $\mathrm{TiO}_{2}$, respectively, as the thermoelectric materials. The unfilled triangles and circles represent the p-type $\mathrm{ZnO}$ (co-doped $\mathrm{ZnO}$ ) and $\mathrm{CuO}$, respectively, as the thermoelectric materials. As seen in Figure $2 \mathrm{a}$, the power output of a single leg based on ntype $\mathrm{ZnO}$ was much higher than the power output of a single leg based on n-type $\mathrm{TiO}_{2}$. Furthermore, the power output of p-type $\mathrm{ZnO}$ was much higher than the p-type $\mathrm{CuO}$, as shown in Figure 2b. In general, the performance of the TEG was governed by the figure of merit (Z), which was proportional to the square of the Seebeck coefficient and the electrical conductivity, and inversely proportional to the thermal conductivity. Thus, $\mathrm{Z}$ can be 
estimated from Table 1 . The $\mathrm{Z}$ of co-doped $\mathrm{ZnO}$ was four orders higher than that of $\mathrm{CuO}$; thus, one of the possible reasons for the different power output values was due to the materials' thermoelectric properties, which compensated for each other.

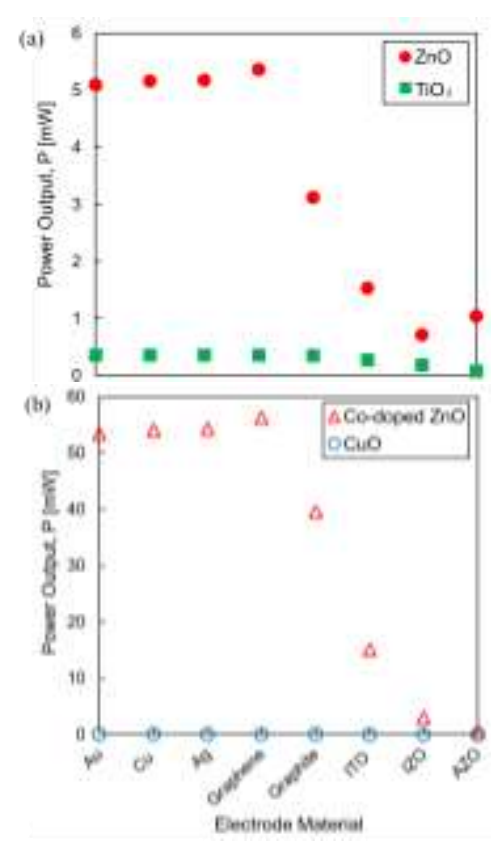

Figure 2 Power output of combination of: (a) n-type; and (b) p-type thermoelectric and electrode materials

Moreover, as seen in Figure 2, the power output of n- and p-type ZnO was significantly influenced by varying the electrode material. For the n-type $\mathrm{ZnO}$, the highest power output was observed when $\mathrm{ZnO}$ was combined with graphene as the electrode, while the lowest power output was observed when $\mathrm{ZnO}$ was combined with IZO as the electrode. The middle power output was obtained when $\mathrm{ZnO}$ was combined with graphite as the electrode. The power output was dependent on the electrode material likely because of the contact resistance between the electrode materials and $\mathrm{ZnO}$, as also observed in the conventional TEG. By considering a series of $\mathrm{ZnO}$ resistance and contact resistances between the electrode and $\mathrm{ZnO}$, the contact resistances were theoretically calculated. Figure 3a shows the theoretically calculated contact resistance for the combination of n-type $\mathrm{ZnO}$ with three electrode materials (graphene, graphite, and IZO). As seen in Figure 3a, the dependency of contact resistance was hardly observed and was not in alignment with the tendency of power output shown in Figure 2a. Thus, the single-leg TEG based on ZnO material was likely not influenced by the contact resistance, in contrast to the conventional TEG mentioned previously.

The difference in thermal conductivity of the electrode material may have influenced the distribution of heat in $\mathrm{ZnO}$, which would alter the produced open-circuit voltage. In order to clarify this influence, the simulated temperature difference and open-circuit voltage of the combination of n-type $\mathrm{ZnO}$ with the three electrode materials (graphene, graphite, and IZO) was plotted (Figure 3b). As seen in Figure 3b, the highest open-circuit voltage was obtained when combining the n-type $\mathrm{ZnO}$ with graphene, while the lowest voltage was obtained when the n-type $\mathrm{ZnO}$ was combined with IZO. This was in good agreement with the dependency of the power output on the electrode material, as shown in Figure 2. As seen in Table 1, graphene has the highest thermal conductivity, and IZO has the lowest thermal conductivity. Thus, a big temperature difference can be provided to the 
$\mathrm{ZnO}$ by using electrode materials with high thermal conductivity, as this will allow a higher open-circuit voltage to be produced. In other words, high thermal conductivity of electrode materials was appropriate for producing high power output due to the large temperature difference allowed in $\mathrm{ZnO}$. Therefore, the combination of $\mathrm{ZnO}$ and graphene was considered the best condition for fabricating the thermopile for TEG based on an oxide semiconductor material.

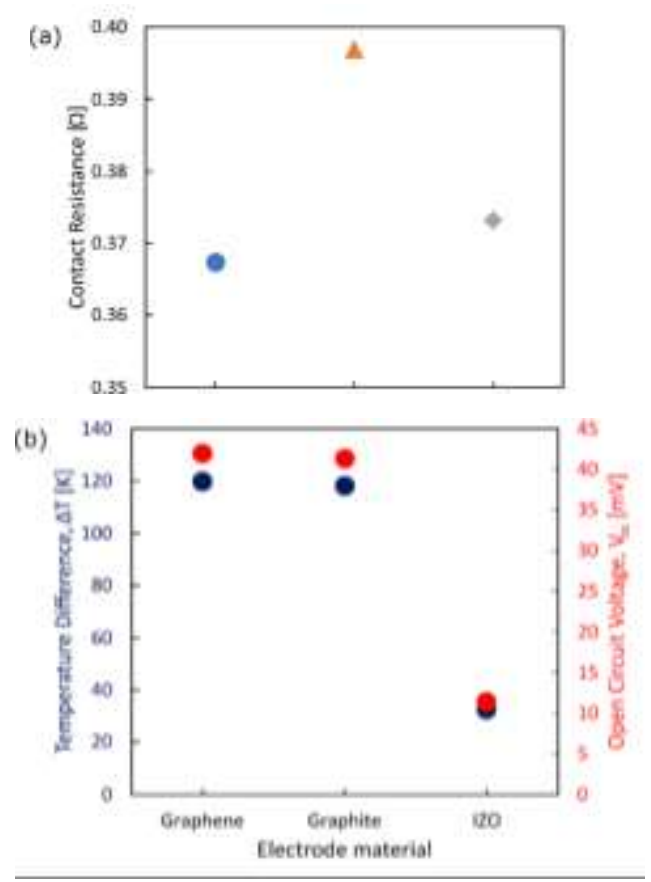

Figure 3 (a) Calculated contact resistance; (b) simulated temperature difference, and open circuit voltage of $\mathrm{ZnO}$ combined with graphene, graphite, and IZO as electrode materials

Figure 4 shows the power output of $\mathrm{n}$ - and p-type $\mathrm{ZnO}$ legs with graphene as electrode materials as a function of its thickness. The filled and unfilled red circles represent the $n-$ and p-type $\mathrm{ZnO}$, respectively. The inset shows the magnified graph for $\mathrm{n}$-type $\mathrm{ZnO}$ legs. As seen in the figure, the power output of both legs decreased with increasing thickness of the electrode; the thickness of $\mathrm{ZnO}$ and the temperature of the top electrode were kept constant. Although the open-circuit voltage was not increased by increasing the thickness of the electrode, the temperature difference in the electrode material was expected to increase. This was further confirmed with the simulated open-circuit voltage and temperature difference of n-type $\mathrm{ZnO}$ and graphene, as shown in Figure 5 and its inset, respectively. By increasing the thickness of graphene, the open-circuit voltage was increased due to the increase in its temperature difference, which resulted in the decrease of the temperature difference of n-type $\mathrm{ZnO}$, as shown in Figure 5. Thus, the decrease in temperature difference of $\mathrm{ZnO}$ resulted in the decrease of its open-circuit voltage, and this decrease was much larger than the increase of the open-circuit voltage of graphene due to the difference in their Seebeck coefficients. Therefore, thin electrodes should be fabricated to produce high power output in TEGs.

Considering the conditions discussed previously, four thermopiles were connected in a series with graphene as the electrode with a thickness of $0.005 \mathrm{~mm}$. Each thermopile consisted of $\mathrm{ZnO}$ and co-doped $\mathrm{ZnO}$ as the $\mathrm{n}$ - and p-type legs, respectively, with a dimension of $1.6 \times 1.4 \times 1.4 \mathrm{~mm}^{3}$, as shown in Figure $1 \mathrm{~b}$. These thermopiles were modeled for comparison with conventional TEGs. Figure 6 shows the simulated power density of the 
modeled TEG, as well as that of the reported conventional TEG based on Te materials (TEGMART; TECTEG; European Thermodynamics). The power density of the proposed TEG was evaluated at a temperature difference of $120 \mathrm{~K}$, and the reported A, B, and C TEGs were evaluated at 300,270 , and $75 \mathrm{~K}$, respectively, in low-temperature application regions. As seen in Figure 6, the proposed TEG based on $\mathrm{ZnO}$ materials was comparable to the conventional TEGs. Therefore, oxide materials have the potential for application as thermoelectric materials in TEGs with proper electrode material combination and structure.

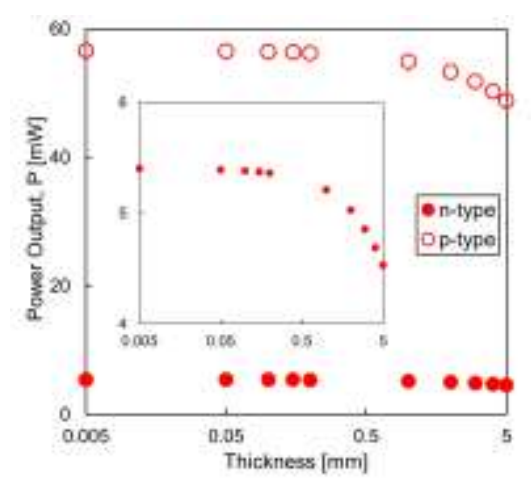

Figure 4 Power output of $\mathrm{n}$ - and p-type $\mathrm{ZnO}$ legs as a function of graphene electrode thickness. The inset shows the magnified graph for n-type ZnO

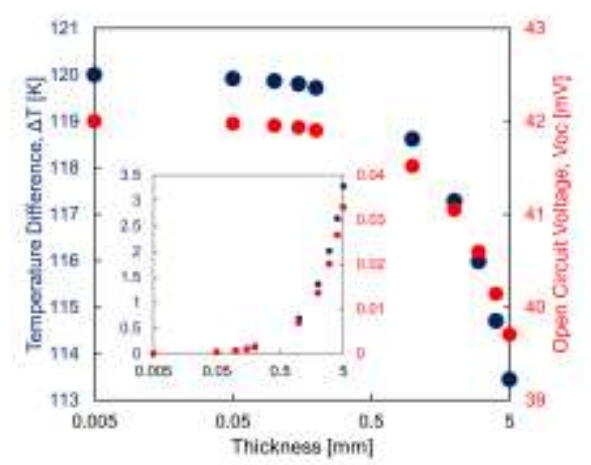

Figure 5 Simulated temperature difference and open-circuit voltage of n-type $\mathrm{ZnO}$ as a function of graphene electrode thickness. The inset shows the simulated temperature difference and opencircuit voltage of graphene

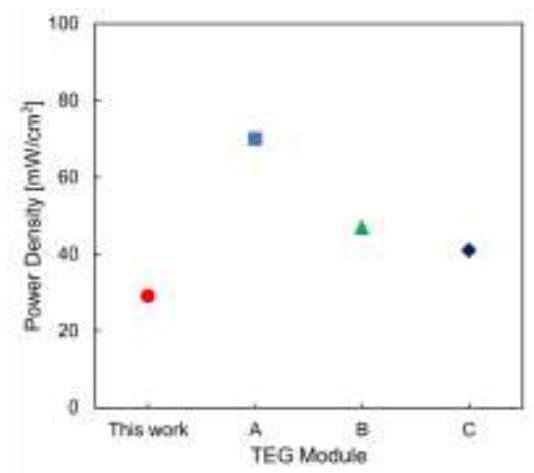

Figure 6 Power density of the simulated and reported TEGs

Additionally, the introduction of nanostructure and optimized doping can further increase the performance of TEG based on oxide semiconductor materials. Since the fabrication processes of oxide materials are relatively simple and established, these 
materials are attractive for application in TEGs. For example, Choi reported a simple fabrication process for fabricating high-density and well-aligned $\mathrm{ZnO}$ nanorods on graphene (Choi et al., 2011). This enabled observations of the benefits of introducing nanostructure and combining $\mathrm{ZnO}$ with graphene as the electrode material.

\section{Conclusions}

In order to propose an efficient TEG based on oxide semiconductor materials, we demonstrated a theoretical calculation of the power output of a TEG based on oxide semiconductors $\left(\mathrm{ZnO}, \mathrm{TiO}_{2}\right.$, and $\left.\mathrm{CuO}\right)$ as thermoelectric materials combined with electrode materials $(\mathrm{Au}, \mathrm{Ag}, \mathrm{Cu}$, graphene, graphite, ITO, IZO, and AZO). The combination of $\mathrm{n}$ - and $\mathrm{p}$ type $\mathrm{ZnO}$ and graphene in the thermopile legs showed the highest power output due to the high thermal conductivity of graphene, which allowed a high temperature difference to be applied in $\mathrm{ZnO}$. Moreover, the power output increased with decreasing thickness of the electrode, which allowed high open-circuit voltage (thermoelectromotive force) to be generated by ZnO. The evaluated power density of the proposed TEG based on optimized conditions was simulated to be $29 \mathrm{~mW} / \mathrm{cm}^{2}$ at a temperature difference of $120 \mathrm{~K}$, which was comparable with the conventional TEG based on Te materials. Therefore, a TEG based on oxide semiconductor materials could be developed to reduce the use of rare and harmful materials in TEGs.

\section{Acknowledgements}

This work was financially supported by the Fundamental Research Grant Scheme (FP092-2020)(FRGS/1/2020/TK0/UM/02/25) from the Ministry of Higher Education and RU Grant-Faculty Program (GPF014A-2019) from Universiti Malaya. The authors would also like to thank the Innovation in Science Pursuit for Inspired Research (INSPIRE) Faculty Program through the Department of Science and Technology (DST) funded by the Ministry of Science and Technology (DST/INSPIRE/04/2017/ 002629).

\section{References}

Amollo, T.A., Mola, G.T., Kirui, M.S.K., Nyamori, V.O., 2017. Graphene for Thermoelectric Applications: Prospects and Challenges. Critical Reviews in Solid State and Materials Sciences, Volume 43(2), pp. 133-157

Abinaya, C., Bethke, K., Andrei, V., Baumann, J., Pollakowski-Herrmann, B., Kanngießer, B., Beckhoff, B., Vásquez, G.C., Mayandi, J., Finstad, T.G., Rademann, K., 2020. The Effect of Post-deposition Annealing Conditions on Structural and Thermoelectric Properties of Sputtered Copper Oxide Films. RSC Advances, Volume 10(49), pp. 29394-29401

Ashida, T., Miyamura, A., Sato, Y., Yagi, T., Taketoshi, N., Baba, T., Shigesato, Y., 2007. Effect of Electrical Properties on Thermal Diffusivity of Amorphous Indium Zinc Oxide Films. Journal of Vacuum Science \& Technology A: Vacuum, Surfaces, and Films, Volume 25(4), pp. 1178-1183

Bang, S.Y., Mocanu, F.C., Lee, T.H., Yang, J., Zhan, S., Jung, S.M., Shin, D.W., Suh, Y.H., Fan, X.B., Lee, S., Choi, H.W., 2020. Robust In-Zn-O Thin-Film Transistors with a Bilayer Heterostructure Design and a Low-Temperature Fabrication Process using Vacuum and Solution Deposited Layers. ACS Omega, Volume 5, pp. 21593-21601

Bian, J.M., Li, X.M., Gao, X.D., Yu, W.D., Chen, L.D., 2004. Deposition and Electrical Properties of N-In Codoped P-Type ZnO Films by Ultrasonic Spray Pyrolysis. Applied Physics Letters, Volume 84(4), pp. 541-543 
Carvill, J., 1994. Mechanical Engineer's Data Handbook. Butterworth-Heinemann, Burlinton, USA, pp. 102-145

Cheng, H., Xu, X.J., Hng, H.H., Ma, J., 2009. Characterization of Al-Doped ZnO Thermoelectric Materials Prepared by RF Plasma Powder Processing and Hot Press Sintering. Ceramics International, Volume 35(8), pp. 3067-3072

Choi, W.M., Shin, K.S., Lee, H.S., Choi, D., Kim, K., Shin, H.J., Yoon, S.M., Choi, J.Y., Kim, S.W., 2011. Selective Growth of $\mathrm{ZnO}$ Nanorods on $\mathrm{SiO}_{2} / \mathrm{Si}$ Substrates using a Graphene Buffer Layer. Nano Research, Volume 4(5), pp. 440-447

Coelho, M.F., Rivas, M.A., Vilão, G., Nogueira, E.M., Iglesias, T.P., 2019. Permittivity and Electrical Conductivity of Copper Oxide Nanofluid (12 nm) in Water at Different Temperatures. The Journal of Chemical Thermodynamics, Volume 132, pp. 164-173

Cusack, N., Kendall, P., 1958. The Absolute Scale of Thermoelectric Power at High Temperature. Proceedings of the Physical Society, Volume 72(5), pp. 898-901

Ebling, D., Bartholomé, K., Bartel, M., Jägle, M., 2010. Module Geometry and Contact Resistance of Thermoelectric Generators Analyzed by Multiphysics Simulation. Journal of Electronic Materials, Volume 39(9), pp. 1376-1380

Endoh, R., Hirano, T., Takeda, M., Oishi, M., Oka, N., Shigesato, Y., 2011. Thermal Conductivity of Amorphous Indium Zinc Oxide Thin Films. MRS Online Proceedings Library (OPL), Volume 1315, pp. 125-130

Fang, L., Yang, X.F., Peng, L.P., Zhou, K., Wu, F., Huang, Q.L., Kong, C.Y., 2010. Thermoelectric and Magnetothermoelectric Properties of In-Doped Nano-ZnO Thin Films Prepared by RF Magnetron Sputtering. Journal of Superconductivity and Novel Magnetism, Volume 23(6), pp. 889-892

Fang, C., Zhang, J., Chen, X., Weng, G.J., 2020. Calculating the Electrical Conductivity of Graphene Nanoplatelet Polymer Composites by a Monte Carlo Method. Nanomaterials, Volume 10(6), pp. 1-15

Fang, J., Vandenberghe, W.G., Fischetti, M.V., 2016. Microscopic Dielectric Permittivities of Graphene Nanoribbons and Graphene. Physical Review B, Volume 94, https://doi.org/10.1103/PhysRevB.94.045318

Ho, C.Y., Powell, R.W., Liley, P.E., 2009. Thermal Conductivity of the Elements. Journal of Physical and Chemical Reference Data, Volume 1(2), pp. 279-421

Han, L.Y., Shu, Y.C., 2016. Study of Large-Scale Aluminium-Doped Zinc Oxide Ceramic Targets Prepared by Slip Casting. Advances in Materials Science and Engineering, Volume 2016, pp. 1-6

Hartung, D., Gather, F., Hering, P., Kandzia, C., Reppin, D., Polity, A., Meyer, B.K., Klar, P.J., 2015. Assessing the Thermoelectric Properties of $\mathrm{Cu}_{\mathrm{x}} \mathrm{O}(\mathrm{x}=1$ to 2) Thin Films as a Function of Composition. Applied Physics Letters, Volume 106(25), https://doi.org/10.1063/1.4923031

Hong, X., Yu, W., Chung, D.D.L., 2017. Electric Permittivity of Reduced Graphite Oxide. Carbon, Volume 111, pp. 182-190

Kanas, N., Bittner, M., Desissa, T.D., Singh, S.P., Norby, T., Feldhoff, A., Grande, T., Wiik, K., Einarsrud, M.A., 2018. All-Oxide Thermoelectric Module with in Situ Formed NonRectifying Complex P-P-N Junction and Transverse Thermoelectric Effect. ACS Omega, Volume 3(8), pp. 9899-9906

Kanas, N., Bjørk, R., Wells, K.H., Schuler, R., Einarsrud, M.A., Pryds, N., Wiik, K., 2020. TimeEnhanced Performance of Oxide Thermoelectric Modules based on a Hybrid P-N Junction. ACS Omega, Volume 6(1), pp. 197-205 
Kitagawa, H., Kunisada, T., Yamada, Y., Kubo, S., 2010. Effect of Boron-Doping on Thermoelectric Properties of Rutile-Type Titanium Dioxide Sintered Materials. Journal of Alloys and Compounds, Volume 508(2), pp. 582-586

Kausar, A., Taherian, R., 2019. Electrical Conductivity in Polymer Composite Filled with Carbon Microfillers. Electrical Conductivity in Polymer-Based Composites: Experiments, Modelling, and Applications, William Andrew, Cambridge, United States, pp. $19-40$

Kinsey, N., DeVault, C., Kim, J., Ferrera, M., Shalaev, V.M., Boltasseva, A., 2015. Epsilon-NearZero Al-Doped ZnO for Ultrafast Switching at Telecom Wavelengths. Optica, Volume 2, pp. 616-622

Kremer, G.O., Chiu, M.C., Lin, C.Y., Gupta, S., Claudio, D., Thevenot, H., 2012. Application of Axiomatic Design, TRIZ, and Mixed Integer Programming to Develop Innovative Designs: A Locomotive Ballast Arrangement Case Study. The International Journal of Advanced Manufacturing Technology, Volume 61, pp. 827-842

Lee, S., Park, H., Paine, D.C., 2011. A Study of the Specific Contact Resistance and Channel Resistivity of Amorphous IZO Thin Film Transistors with IZO Source-Drain Metallization. Journal of Applied Physics, Volume 109, https://doi.org/10.1063/1.3549810

Li, Q.Y., Xia, K., Zhang, J., Zhang, Y., Li, Q., Takahashi, K., Zhang, X., 2017. Measurement of Specific Heat and Thermal Conductivity of Supported and Suspended Graphene by a Comprehensive Raman Optothermal Method. Nanoscale, Volume 9, pp. 10784-10793

Lim, C.H., Choi, S.M., Seo, W.S., Lee, M.H., Lee, K.H., Park, H.H., 2013. A Study of Electrodes for Thermoelectric Oxides. Electronic Materials Letters, Volume 9(4), pp. 445-449

Luo, Y., Kim, C.N., 2019. Effects of the Cross-Sectional Area Ratios and Contact Resistance on the Performance of a Cascaded Thermoelectric Generator. International Journal of Energy Research, Volume 43(6), pp. 2172-2187

Luo, J.T., Zheng, Z.H., Liang, G.X., Li, F., Fan, P., 2017. Enhanced Thermoelectric Properties in AZO Thin Films by Introducing Ti Co-Dopant. Materials Research Bulletin, Volume 94, pp. 307-312

Loureiro, J., Neves, N., Barros, R., Mateus, T., Santos, R., Filonovich, S., Reparaz, S., Sotomayor-Torres, C.M., Wyczisk, F., Divay, L., Martins, R., Ferreira, I., 2014. Transparent Aluminium Zinc Oxide Thin Films with Enhanced Thermoelectric Properties. Journal of Materials Chemistry A, Volume 2(18), pp. 6649-6655

Matsubara, I., Funahashi, R., Takeuchi, T., Sodeoka, S., Shimizu, T., Ueno, K., 2001. Fabrication of an All-Oxide Thermoelectric Power Generator. Applied Physics Letters, Volume 78(23), pp. 3627-3629

Matula, R.A., 2009. Electrical Resistivity of Copper, Gold, Palladium, and Silver. Journal of Physical and Chemical Reference Data, Volume 8(4), pp. 1147-1298

Musiał, M., Borcuch, M., Wojciechowski, K., 2016. Performance Calculations of Thermoelectric Module P-Type Leg Composed of (Bi2Te3)x(Sb2Te3)1-x. E3S Web of Conferences, Volume 10, pp. 1-6

Narducci, D., 2019. Thermoelectric Harvesters and the Internet of Things: Technological and Economic Drivers. Journal of Physics: Energy, Volume 1(2), pp. 1-12

Ozaki, H., Kurimoto, M., Sawada, T., Funabashi, T., Kato, T., Suzuoki, Y., 2017. Evaluation of Relative Permittivity and Coefficient of Thermal Expansion of $\mathrm{TiO}_{2} / \mathrm{SiO}_{2}$ Epoxy Composites for Permittivity-Graded Insulator. In: IEEE Conference on Electrical Insulation and Dielectric Phenomenon (CEIDP), pp. 568-571 
Peyghambarzadeh, S.M., Hashemabadi, S.H., Naraki, M., Vermahmoudi, Y., 2013. Experimental Study of Overall Heat Transfer Coefficient in the Application of Dilute Nanofluids in the Car Radiator. Applied Thermal Engineering, Volume 52, pp. 8-16

Thuau, D., Koymen, I., Cheung, R., 2011. A Microstructure for Thermal Conductivity Measurement of Conductive Thin Films. Microelectronic Engineering, Volume 88(8), pp. 2408-2412

Vieira, E.M., Silva, J.P., Veltruská, K., Istrate, C.M., Lenzi, V., Trifiletti, V., Lorenzi, B., Matolín, V., Ghica, C., Marques, L., Fenwick, O., 2021. All-Oxide P-N Junction Thermoelectric Generator based on SnO x and ZnO Thin Films. ACS Applied Materials \& Interfaces, Volume 13(29), pp. 35187-35196

Vendra, S.K., Chrzanowska-Jeske, M., 2019. Thermal Management in 3D IC Designs for Nano-CMOS Technologies: Analysis on Graphene- Vs. Graphite-Based TIM. In: 2018 IEEE 13 ${ }^{\text {th }}$ Nanotechnology Materials and Devices Conference (NMDC), pp. 1-4

Wu, C.Y., Thanh, T.V., Chen, Y.F., Lee, J.K., Lin, J.J., 2010. Free-Electronlike Diffusive Thermopower of Indium Tin Oxide Thin Films. Journal of Applied Physics, Volume 108(12), https://doi.org/10.1063/1.3524522

Yin, J., Zhou, J., Li, X., Chen, Y., Tai, G., Guo, W., 2011. Enhanced Gas-Flow-Induced Voltage in Graphene. Applied Physics Letters, Volume 99(7), https://doi.org/10.1063/1.3624590 